\title{
Differential effects of an alpha-2 agonist on wakefulness and paradoxical sleep in the rat: A polygraphic and biochemical approach
}

\author{
Z. de Saint Hilaire, F. Karege, J.-M. Gaillard and R. Blois \\ Hopitaux Universitaires de Geneve, Service de Neuropsychiatrie, \\ 2 Chemin du Petit Bel Air, 1225 Chene-Bourg, Switzerland
}

Correspondence to: Z. de Saint Hilaire at above address

\begin{abstract}
The purpose of this experiment was to determine the sensitivity of wakefulness and paradoxical sleep to the $\alpha 2$-agonist clonidine. The drug inhibited both wakefulness and paradoxical sleep but the smallest dose necessary to inhibit wakefulness was 64 times larger than the smallest dose inhibiting paradoxical sleep. The effect on paradoxical sleep was inhibitory for all the clonidine doses but wakefulness was enhanced transiently after the four largest doses used. The time between injection and maximum wakefulness enhancement was highly correlated with the dose of clonidine. The brain level measured after these four different doses at the moment of maximum wakefulness enhancement was the same, suggesting that this effect occurred only when a critical concentration of the drug was attained in the brain and not when the concentration was higher or lower. These data suggest that different $\alpha 2$-adrenoceptors are involved in these two states of vigilance or, alternatively, that their sensitivity is modulated physiologically. In addition, a sensitivity imbalance between different $\alpha 2$-adrenoceptors may exist in wakefulness but not in paradoxical sleep.
\end{abstract}

Keywords: Alpha2-adrenoceptors - Clonidine - Paradoxical sleep - Rat - Wakefulness

\section{INTRODUCTION}

Clonidine (CLN), an imidazoline derivative, is a potent agonist of $\alpha 2$-adrenoceptors. It enhances the brain concentration of noradrenaline (NA) and decreases the concentration of 3-methoxy-4-hydroxyphenylglycol (MHPG) (Starke and Altmann, 1973; Braestrup, 1974; Forray et al., 1995). These modifications correspond to a decrease in the turnover of NA resulting from the activation of presynaptic $\alpha 2$-adrenoceptors (Anden et al., 1976). There is now ample evidence that the release of the transmitter is controlled by a negative feedback mediated by $\alpha 2$-adrenoceptors (Langer, 1974). However, it seems probable that $\alpha 2-$ adrenoceptors can also be found on non-NA neurones or terminals (Young and Kuhar, 1980; De-Boer and Ruigt, 1995).

Besides its well known antihypertensive effect, CLN also has sedative actions mediated by $\alpha 2$-adrenoceptors (Delbarre and Schmitt, 1971; Florio et al., 1975; Drew et al., 1979; Angel and Majeed, 1990; Head, 1995). In addition, this compound is a powerful inhibitor of paradoxical sleep (PS) (Kleinlogel et al., 1975; Autret et al., 1977; Gaillard and Kafi, 1979; Mastrangelo et al., 1994). Since NA is an important transmitter for both wakefulness and PS, it can be rea- sonably assumed that the decrease of wakefulness and PS induced by CLN is related to the agonist action on $\alpha 2$-adrenoceptors and the decrease of firing of NA neurones (Aghajanian et al., 1977; Aghajanian and van der Maelen, 1982).

In the present experiment, we studied the effects of different doses of CLN on wakefulness and PS in the rat in order to determine if these two states of vigilance would show equal sensitivity to CLN, that is, if a given dose of CLN would affect wakefulness and PS to the same extent. Also, the level of CLN in different brain areas after the four doses producing enhancement, at the times at which the increase of wakefulness was maximal, was determined.

\section{METHODS}

\section{Electrophysiological experiments}

Male albino Wistar rats (250-300 g) were chronically implanted, under pentobarbitone anaesthesia (55 mg. $\mathrm{kg}^{-1}$ ), with four electrodes for EEG recordings, two for the eye movements and two for the electromyogram from the neck muscles.

Following surgery, the rats were placed individually 
in their recording cages and were allowed at least two weeks for recovery before the experimental sessions. A light-dark schedule (light period: $7 \mathrm{am}$ to $7 \mathrm{pm}$ ) was maintained and the animals had free access to food and water.

In order to investigate the dose/effect relationship of CLN on vigilance states, the following doses were given: $0.0025,0.005,0.01,0.02,0.04,0.08,0.16$ and $0.32 \mathrm{mg} . \mathrm{kg}^{-1}$. The recordings were started at $7 \mathrm{am}$ and the drug was given by intraperitoneal injection at $8 \mathrm{am}$. The different doses were given to different animals. Sixteen control rats were given the vehicle only (sodium chloride, $0.9 \%$ ). The recordings lasted until the onset of the dark period, thus providing a period of observation of 11 hours. Hypothermia induced by CLN (Maj et al., 1975) was prevented by keeping the animals at a temperature of $25^{\circ} \mathrm{C}$ within the recording cages.

Three states of vigilance were scored visually: wakefulness (W), orthodox sleep and PS. The state of vigilancè was determined every 20 seconds during each of the 11 hours recordings following the injection. The classical sleep parameters and the general trends of $\mathrm{W}$ and PS were calculated using a special software package designed for the interpretation of sleep data.

Sleep latency is the time interval between the clonidine injection and the first episode of sleep. The duration of a sleep cycle is defined by the number of minutes of sleep between the end of an episode of PS and the end of the next one. The efficiency index is the ratio of total sleep to total recording time. The latency of PS is the number of minutes between the onset of sleep and the first appearance of PS. The organisation index is the ratio of sleep within complete cycles (i.e. not interrupted by W) to total sleep.

The evolution of $\mathrm{W}$ as a function of clock time and PS as a function of sleep time can be described by the general trend of W and PS, respectively. These general trends were obtained by adding the occurrences of vigilance states and fitting the sum of the occurrences by orthogonal polynomials (Gaillard, 1979). The instantaneous trend of the vigilance states is the first derivative of the general trend. This function is defined for every minute of clock time or sleep time by a number between 0 and 1 . These numbers represent the probability of $\mathrm{W}$ in every minute of clock time or of PS in every minute of sleep time, respectively. Thus, if the instantaneous trend of $\mathrm{W}$ at minute 300 of the recording is 0.55 , this means that the animal has, on average, a probability of 0.55 to spend this minute in $\mathrm{W}$.

\section{Biochemical experiments}

Four groups (A, B, C and D) of male albino rats $(250 \mathrm{~g})$ received $0.04,0.08,0.16$ and $0.32 \mathrm{mg} \cdot \mathrm{kg}^{-1}$ of
CLN by intraperitoneal injection, respectively. $25 \mathrm{pci}$ of $\mathrm{H}^{3}$-clonidine per rat was added to each solution of CLN. The rats in each group were decapitated after a period corresponding to the maximum of the instantaneous trend of $\mathrm{W}$ determined in sleep recordings, i.e. at 34, 263, 463 and 628 minutes, respectively, for groups A, B, C and D. After decapitation, the brains were removed immediately and dissected into three parts: cortex, pons and remainder of the brain. These parts were weighed and then digested in $4 \mathrm{ml}$ of NCS solubiliser (Beckman, Switzerland) at $50^{\circ} \mathrm{C}$. After complete digestion, a known volume of the solution, namely $2 \mathrm{ml}$, was added to $15 \mathrm{ml}$ of PPO in scintillation vials. The vials were then kept at $40^{\circ} \mathrm{C}$ for one hour. Liquid scintillation counting was carried out in a Searle (R) scintillation spectometer (model Delta 300) and radioactivity was calculated using a calibration curve, drawn previously.

CLN concentrations were determined in the cortex, the pons and the remainder of the brain. Each group contained five rats.

For the statistical evaluation of experiments, all the parameters were tested by one-way analysis of variance (ANOVA) and post hoc comparison by Student's $t$ tests.

\section{RESULTS}

No significant differences were found for any sleep parameters after the smallest dose of CLN. The most sensitive parameter was the latency of PS, which was significantly enhanced after each dose of CLN higher than $0.0025 \mathrm{mg} \cdot \mathrm{kg}^{-1}$ (Table I). After doses of $0.0025 \mathrm{mg} . \mathrm{kg}^{-1}$, the number of sleep cycles was greater, an effect not seen with higher doses. The total duration of PS was slightly and nonsignificantly increased and the slope of the general trend was steeper than in the controls (not shown); this indicates that, after the initial inhibitory effect observed on PS latency, the production of PS was slightly higher than in the controls.

After each dose equal to or higher than $0.01 \mathrm{mg} \cdot \mathrm{kg}^{-1}$, the total duration of PS, the number of sleep cycles and the organisation index were dose-dependently decreased (Table I). Interestingly enough, the average duration of PS episodes was not modified at doses below $0.01 \mathrm{mg} \cdot \mathrm{kg}^{-1}$ and was dose-dependently reduced with increasing doses. The $0.32 \mathrm{mg} \cdot \mathrm{kg}^{-1}$ dose of CLN totally suppressed PS.

No alteration of $\mathrm{W}$ appeared below doses of $0.04 \mathrm{mg} \cdot \mathrm{kg}^{-1}$. After doses of 0.04 and $0.08 \mathrm{mg} \cdot \mathrm{kg}^{-1}, \mathrm{~W}$ was significantly enhanced and the efficiency index was reduced (Table I). After $0.08 \mathrm{mg} \cdot \mathrm{kg}^{-1}$, the number of awakenings was significantly greater than in the con- 
TABLE I. Modifications in sleep variables after intraperitoneal injection of $\mathrm{NaCl}$ or clonidine

\begin{tabular}{|c|c|c|c|c|c|c|c|c|c|}
\hline Variables (min) & $\mathrm{NaCl}$ & $\begin{array}{c}0.0025 \\
\mathrm{mg} \cdot \mathrm{kg}^{-1}\end{array}$ & $\begin{array}{c}0.005 \\
\mathrm{mg} \cdot \mathrm{kg}^{-1}\end{array}$ & $\begin{array}{c}0.01 \\
\mathrm{mg} \cdot \mathrm{kg}^{-1}\end{array}$ & $\begin{array}{c}0.02 \\
\mathrm{mg} \cdot \mathrm{kg}^{-1}\end{array}$ & $\begin{array}{c}0.04 \\
\mathrm{mg} \cdot \mathrm{kg}^{-1}\end{array}$ & $\begin{array}{c}0.08 \\
\mathrm{mg} \cdot \mathrm{kg}^{-1}\end{array}$ & $\begin{array}{c}0.16 \\
\mathrm{mg} \cdot \mathrm{kg}^{-1}\end{array}$ & $\begin{array}{c}0.32 \\
\mathrm{mg} \cdot \mathrm{kg}^{-1}\end{array}$ \\
\hline & $n=16$ & $n=7$ & $n=6$ & $\mathrm{n}=8$ & $n=6$ & $n=6$ & $n=6$ & $\mathrm{n}=6$ & $n=6$ \\
\hline Total sleep & $458 \pm 40$ & $459 \pm 39$ & $451 \pm 39$ & $438 \pm 53$ & $444 \pm 36^{\star \star \star}$ & $379 \pm 35^{\star \star \star}$ & $349 \pm 46^{\star \star \star}$ & $387 \pm 189$ & $446 \pm 117$ \\
\hline Waking & $202 \pm 39$ & $201 \pm 42$ & $209 \pm 39$ & $222 \pm 62$ & $216 \pm 43$ & $281 \pm 36$ & $311 \pm 46^{\star \star \star}$ & $273 \pm 91$ & $214 \pm 117$ \\
\hline Slow wave sleep & $380 \pm 42$ & $381 \pm 33$ & $388 \pm 49$ & $384 \pm 40$ & $403 \pm 36$ & $352 \pm 45$ & $335 \pm 44^{*}$ & $386 \pm 89$ & $406 \pm 117$ \\
\hline Sleep latency & $10 \pm 12$ & $20 \pm 10$ & $6 \pm 5$ & $15 \pm 6$ & $16 \pm 8$ & $17 \pm 8$ & $9 \pm 5$ & $7 \pm 6$ & $6 \pm 3$ \\
\hline Number of awakenings & $132 \pm 30$ & $135 \pm 32$ & $170 \pm 48^{\star}$ & $146 \pm 33$ & $123 \pm 22$ & $170 \pm 51$ & $217 \pm 41^{* \star \star}$ & $178 \pm 20^{\star}$ & $196 \pm 49^{* * *}$ \\
\hline cycles & $11.0 \pm 2.2$ & $9.5 \pm 1.3$ & $10.0 \pm 1.2$ & $10.7 \pm 1.1$ & $9.9 \pm 0.7$ & $9.0 \pm 2.0$ & $8.0 \pm 3.0$ & $10.0 \pm 7.0$ & - \\
\hline Efficiency index & $0.69 \pm 0.06$ & $0.70 \pm 0.62$ & $068 \pm 0.59$ & $0.67 \pm 0.90$ & $0.69 \pm 0.64$ & $0.58 \pm 0.52^{\star}$ & $0.53 \pm 0.70$ & $0.59 \pm 0.14$ & $0.62 \pm 0.18$ \\
\hline Paradoxical sleep & $70 \pm 10$ & $78 \pm 12$ & $63 \pm 19$ & $54 \pm 17^{* \star}$ & $41 \pm 5^{\star \star}$ & $26 \pm 15^{\star \star \star}$ & $14 \pm 12^{\star \star \star}$ & $1.0 \pm 1.4^{\star \star \star}$ & 0 \\
\hline PS latency & $13 \pm 6$ & $26 \pm 7^{\star \star \star}$ & $88 \pm 44^{\star \star *}$ & $115 \pm 33^{\star \star \star}$ & $169 \pm 37^{\star \star \star}$ & $216 \pm 65^{\star \star \star}$ & $260 \pm 67^{\star \star \star}$ & $384 \pm 18^{* \star \star}$ & - \\
\hline Organisation index & $0.85 \pm 0.05$ & $0.84 \pm 0.57$ & $0.68 \pm 0.18^{\star}$ & $0.64 \pm 0.15^{\star \star \star}$ & ${ }^{\star} 0.59 \pm 0.56^{\star \star \star}$ & $0.42 \pm 0.16^{\star \star \star}$ & $0.25 \pm 0.20^{\star \star \star}$ & $0.60 \pm 0.92^{\star \star *}$ & - \\
\hline Number of sleep cycles & $35 \pm 5$ & $41 \pm 6^{*}$ & $31 \pm 9$ & $26 \pm 7^{\star \star}$ & $25 \pm 3^{\star \star \star}$ & $17 \pm 7^{\star \star \star}$ & $10 \pm 7^{\star \star \star}$ & $2 \pm 3^{\star \star \star}$ & 0 \\
\hline episodes & $2.1 \pm 0.2$ & $2.0 \pm 0.2$ & $2.1 \pm 0.2$ & $2.1 \pm 0.3$ & $1.7 \pm 0.3^{*}$ & $2 \pm 0.4^{\star \star \star}$ & $1.4 \pm 0.5^{\star}$ & $0.5 \pm 0.2^{\star \star \star}$ & - \\
\hline
\end{tabular}

Values of the main parameters of vigilance states in the rat under the effect of various doses of clonidine. All durations are in minutes \pm SD for controls;
in the other columns only the mean is indicated. $p<0.05 ; * *: p<0.01 ; * * *: p<0.005$.

The statistical estimations have been made with the Student's t-test after previous estimations of homogeneity of the variances. Every dose of CLN was 

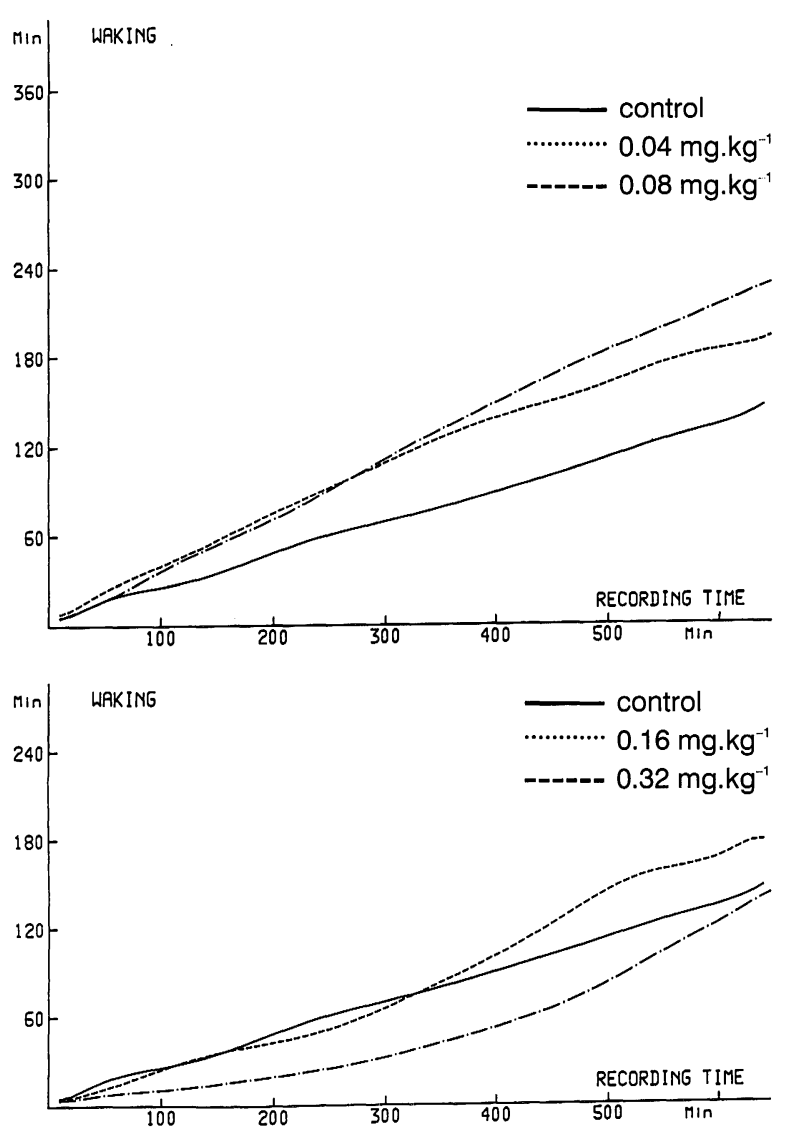

FIG. 1. General trends for wakefulness after different doses of clonidine.

trols. These changes were less evident after $0.16 \mathrm{mg} \cdot \mathrm{kg}^{-1}$, and the efficiency index was enhanced after doses of $0.32 \mathrm{mg} \cdot \mathrm{kg}^{-1}$. Sleep latency, very stable after lower doses of CLN, decreased after doses of 0.16 and $0.32 \mathrm{mg} \cdot \mathrm{kg}^{-1}$, although not significantly.

The general trend of $\mathrm{W}$ was the same as in the controls after doses lower than $0.04 \mathrm{mg} \cdot \mathrm{kg}^{-1}$. After this dose, the production of $\mathrm{W}$ was high initially but at later times in the recording, it tended to return to control values (Figure 1). After doses $0.08 \mathrm{mg} \cdot \mathrm{kg}^{-1}$, the initial part of the curve was almost identical to the controls and an increase occurred later. After doses of $0.16 \mathrm{mg} \cdot \mathrm{kg}^{-1}$, the production of $\mathrm{W}$ was lower during the first five hours than in the controls and an enhancement appeared only in the last six hours of the recording. After doses of $0.32 \mathrm{mg} \cdot \mathrm{kg}^{-1}$, the increase of $\mathrm{W}$ occurred only at the very end of the recording and compensated for the initial decrease so that the total duration of $\mathrm{W}$ was similar to the controls (Figure 1). The decrease of $\mathrm{W}$ observed shortly after the injection of $0.16 \mathrm{mg} \cdot \mathrm{kg}^{-1}$ indicates that this is the threshold dose for the sedative effect of CLN.

These observations suggest that the production of $\mathrm{W}$ was not evenly distributed during the 11 hours of recording time but that it increased markedly during a limited period of time. In order to find out if the time of this increase was related to the dose of CLN, the fitting coefficients of the cumulated occurrence of $\mathrm{W}$ were calculated up to the 11 th degree. This degree was selected in order to make sure that small fluctuations of W were not filtered out by the fitting procedure. The residual variability after fitting this degree was less than $0.03 \%$ and no noteworthy component seemed to exist for higher degrees. For each of the four doses of $0.04,0.08,0.16$ and $0.32 \mathrm{mg} \cdot \mathrm{kg}^{-1}$, the maximum value of the instantaneous trend of $\mathrm{W}$ was calculated. These values were between 0.56 and 0.63 for the four doses. The maximum value found in the controls was 0.47 . In Figure 2, the time of the recording of the highest value of the average instantaneous trend of $\mathrm{W}$ is plotted as a function of the log of CLN dose. It can be seen that these two variables are linearly related, with a correlation coefficient of $0.984(p<0.01)$.

If we take into account the reduction of CLN concentration during the elimination phase of the drug, the fact that the transient enhancement of W occurred with at least five hours delay after higher doses suggests that this effect could be provoked by a critical concentration of CLN in the brain. This hypothesis was tested by determination of the level of CLN after the

TABLE II. Level of clonidine in three brain areas

\begin{tabular}{lcccc}
\hline Group & A & B & C & D \\
\hline CLN mg. $\mathrm{kg}^{-1}$ & 0.04 & 0.08 & 0.16 & 0.32 \\
Time of decapitation after injection $(\mathrm{min})$ & 34 & 263 & 463 & 628 \\
Cortex & $44.1 \pm 8.5$ & $39.1 \pm 7.4$ & $45.5 \pm 8.2$ & $41.6 \pm 3.6$ \\
Pons & $34.2 \pm 5.4$ & $37.4 \pm 3.8$ & $50.2 \pm 10.5$ & $56.5 \pm 16.1$ \\
Remainder of the brain & $51.4 \pm 8.9$ & $65.7 \pm 2.5$ & $56.8 \pm 13.7$ & $55.0 \pm 4.8$ \\
\hline
\end{tabular}

The animals received intraperitoneal injections of $0.04,0.08,0.16$ and $0.32 \mathrm{mg} \cdot \mathrm{kg}^{-1}$ of clonidine and the determinations were made $34,263,463$ and 628 minutes after the injections, respectively. These periods correspond to the maximum value of the instantaneous trend of wakefulness for the respective doses. The levels of clonidine in the four groups of rats are not different in the cortex and the remainder of the brain (ANOVA F-test, $p>0.05$ ) but they are significantly different in the pons $p>0.05$ ). 


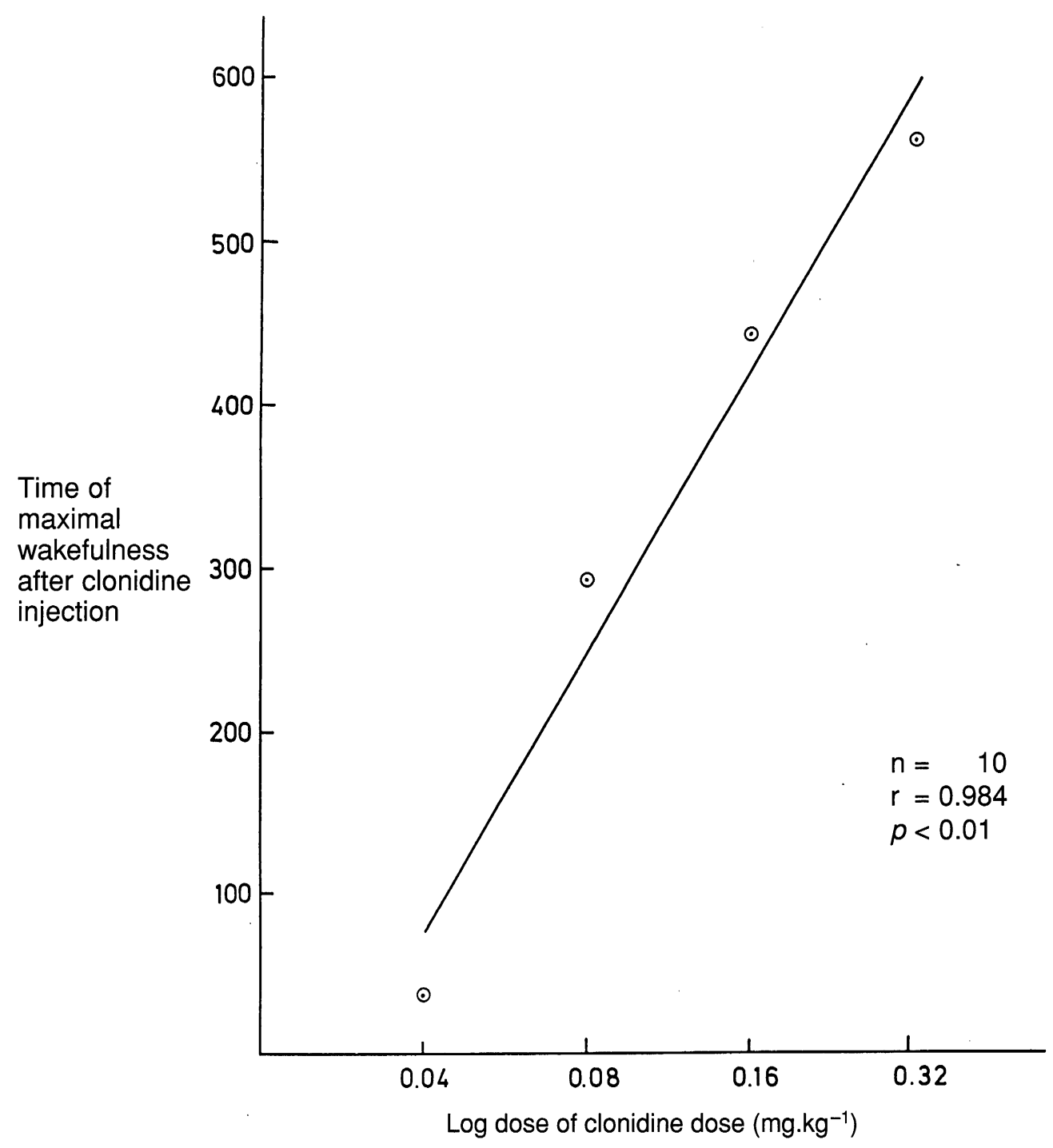

FIG. 2. Relationship between clonidine and time of maximal increase in wakefulness after four doses of clonidine.

four doses producing an enhancement of $\mathrm{W}$ at the times at which this enhancement was maximum, as determined in the polygraph recordings. These times were 34 minutes after 0.04 mg. $\mathrm{kg}^{-1}, 263$ minutes after $0.08 \mathrm{mg} \cdot \mathrm{kg}^{-1}, 463$ minutes after $0.16 \mathrm{mg} \cdot \mathrm{kg}^{-1}$ and 628 minutes after $0.32 \mathrm{mg} \cdot \mathrm{kg}^{-1}$. The results shown in Table II indicate that the levels of CLN in the cortex and the remainder of the brain were similar at these four doses whereas a slight increase was observed in the pons as a function of CLN dose $(p<0.05)$.

\section{DISCUSSION}

CLN inhibits the firing of NA neurones by stimulating $\alpha 2$-adrenoceptors on the NA cell body (Svensson et al., 1975; Cedarbaum and Aghajanian, 1977; Bradley et al., 1995). The present data show that CLN inhibits both PS and W in agreement with previous results (Delbarre and Schmitt, 1971; Autret et al., 1977; Gaillard and Kafi, 1979; Gaillard et al., 1988). However, PS is much more sensitive to CLN than W and the threshold dose for PS inhibition is $0.0025 \mathrm{mg} \cdot \mathrm{kg}^{-1}$ whereas $\mathrm{W}$ inhibition requires a dose 64 times larger ( $0.16 \mathrm{mg} . \mathrm{kg})$.

Two interpretations of this difference can be proposed. Previous data indicate that NA neurones are involved in W and PS but it is likely that different NA neurones are active in these two states of vigilance (Cespuglio et al., 1982; Gaillard et al., 1982; Seidel et al., 1995). Therefore, the different sensitivities of $\mathrm{W}$ 
and PS to CLN may be due to an action of the drug on two different populations of $\alpha 2$-adrenoceptors with different sensitivities. Alternatively, it is possible that a modulation of receptor sensitivity occurs in physiological conditions with high sensitivity in PS and low sensitivity in W. The differential effect of CLN in W and PS would, thus, reflect a variation in the sensitivity of $\alpha 2$-adrenoceptors .

In their autoradiographic study, Young and Kuhar (1980) found a widespread distribution of $\alpha 2$-adrenoceptors in the rat brain. Some of these are present in nuclei containing NA neurones (Cedarbaum and Aghajanian, 1977; Groves and Wilson, 1980a; Groves and Wilson, 1980b) but also on terminals of the NA systems in the effector fields. Thus, $\alpha 2$-adrenoceptors seem to be more dense in areas receiving innervation from the lateral tegmental nuclei (Palacios and Kuhar, 1982). Since it has been proposed that these nuclei can be involved in the realisation of PS (Cespuglio et al., 1982) the particular distribution of $\alpha 2$-adrenoceptors could also be responsible for the different sensitivity of $\mathrm{W}$ and PS to CLN.

Furthermore, in rats, CLN administered into the third ventricle produced sedation and sleep and a dose-dependent increase in electrocortical power voltage; much lower doses were shown to produce similar effects after either unilateral or bilateral microinfusion of CLN into the locus coeruleus (De Sarro et al., 1987). Doses of CLN equimolar to those administered into third ventricle were shown to be ineffective after infusion into the dorsal hippocampus (De Sarro et al., 1987). In all, these results strongly suggest that CLN acts through different $\alpha 2$-adrenoceptors in a different area of the brain.

None of the doses of CLN used in this experiment produced a direct increase of PS. Research conducted in this laboratory over the past few years, in agreement with these results, suggests that the enhancement of PS seen with doses of $0.0025 \mathrm{mg} . \mathrm{kg}^{-1}$ was probably an indirect rebound effect since this dose significantly augmented PS latency (see Table I). Thus, this must probably be regarded as a more remote consequence and not as a direct effect of CLN. We have shown that this effect is suppressed if the animals have been pretreated with a small dose of alpha-methylparatyrosine 24 hours earlier (Kafi and Gaillard, 1981). It may be similar to the rebound observed in similar conditions in man (Gaillard et al., 1983).

However, some doses of CLN induced an increase in $\mathrm{W}$ and the time at which this increase occurred was strictly dose-dependent. This suggests that increase in $\mathrm{W}$ can only occur when a precise level of CLN is reached in the brain but not at higher or lower levels.
This critical level is about $40 \mathrm{ng} \cdot \mathrm{g}^{-1}$; it is reached shortly after doses of $0.04 \mathrm{mg} . \mathrm{kg}^{-1}$ of CLN and later for larger doses due to the kinetics of CLN elimination. This is compatible with the rapid penetration of CLN into the brain of rats (Paalzow and Edlung, 1979a). The increase of $\mathrm{W}$ cannot be due to variations in blood pressure, since the time course of the effect of CLN on this parameter is very different (Paalzow and Edlund, 1979b).

Studies using radiolabelled CLN have shown a large volume of distribution of this drug in kidneys, liver, plasma and other tissues. This has also been shown in the brain where the drug penetrates easily due to its lipid solubility (Lowenthal, 1980; Paalzow and Edlund, 1979a; Darda, 1978). A few minutes after administration, the concentration of CLN in the brain is far greater than the plasma concentration (Lowenthal, 1980).

In vivo, the drug undergoes a series of biotransformations (metabolism and excretion of unchanged molecule) (Darda, 1978). The method used here for the assay of CLN does not differentiate between the parent drug and its metabolites. The latter are known to increase considerably in the plasma, liver and kidneys but it has been shown, by a radio-thinlayerchromatography technique, that concentrations in the brain represent predominantly unchanged CLN (Darda, 1975; Darda et al., 1978). For this reason, it can be assumed that a $40 \mathrm{ng} \cdot \mathrm{g}^{-1}$ concentration in the cortex is reached at the maximum of the instantaneous trend of W. A slightly higher level is found in the remaining part of the brain and this may indicate that very small concentrations of metabolites may be present. But since metabolism essentially proceeds by splitting of the imidazolidine ring, pharmacologically active metabolites are not formed (Darda, 1975; Darda et al., 1978).

Mauron et al. (1980) observed that a dose of $0.05 \mathrm{mg} \cdot \mathrm{kg}^{-1}$ of CLN increased total food and protein consumption in the hour following the injection. This effect disappeared subsequently and did not occur at all after doses of CLN as high as $0.2 \mathrm{mg} \cdot \mathrm{kg}^{-1}$. Thus, the dose of the drug and the time course of the effect were identical to those of the present study. Similarly, Sanger (1983) found an increase in water and food consumption after doses between 0.01 and $0.1 \mathrm{mg} . \mathrm{kg}^{-1}$ of CLN. A dose as low as $0.01 \mathrm{mg} \cdot \mathrm{kg}^{-1}$ induced a limited but significant effect whereas no effect was observed in the present experiment after such a low dose. In addition, the increase of water intake lasted much longer; these observations indicate that enhancement of $\mathrm{W}$ was probably not a mere consequence of increased eating and drinking.

The threshold dose for $\mathrm{W}$ increase is $0.04 \mathrm{mg} \cdot \mathrm{kg}^{-1}$ or 
four times less than the threshold dose for $\mathrm{W}$ inhibition. A similar difference is not apparent in PS. This may reflect an imbalance between different types of $\alpha 2$-adrenoceptors or between different localisation of $\alpha 2$-adrenoceptors (i.e. on NA cell bodies). When the threshold concentration of CLN inducing W increase is reached, the agonist action predominates on the slightly more sensitive presynaptic $\alpha 2$-adrenoceptors and the release of the transmitter is reduced. At higher concentrations of CLN, the postsynaptic action predominates and the firing of NA neurones is decreased. However, this interpretation is one among several possibilities and it cannot, at present, be ascertained that CLN enhances W transiently by acting on $\alpha 2$ adrenoceptors situated on NA neurones.

Other brain structures also contain $\alpha 2$-adrenoceptors, particularly serotonergic terminals, which may be involved hypothetically in some of the effects of CLN (Svensson et al., 1975; Gothert et al., 1981; Reinhard and Roth, 1982). However, the affinity of CLN for serotonergic receptors is lower than that for $\alpha 2$ adrenoceptors .

In conclusion, a sensitivity imbalance between different $\alpha 2$-adrenoceptors may exist in $\mathrm{W}$ but not in PS.

\section{REFERENCES}

Aghajanian GK, Cedarbaum JM and Wang RY (1977) Evidence for norepinephrine-mediated collateral inhibition of locus coeruleus neurons. Brain Research, 136, 570-577.

Aghajanian GK and van der Maelen CP (1982) $\alpha 2$-adrenoceptors-mediated hyperpolarization of locus coeruleus neurons: Intracellular studies in vivo. Science, 215, 1394-1396.

Anden N-E, Grabowska M and Strombom U (1976) Different alpha-adrenoceptors in the central nervous system mediating biochemical and functional effects of clonidine and receptor blocking agents. NaunynSchmiedeberg's Archives of Pharmacology, 292, 43-52.

Angel A and Majeed ABA (1990) Alterations of sleeping time in the rat induced by drugs which modulate central monoaminergic systems. British Journal of Anaesthesia, 64/5, 594-600.

Autret A, Minz M, Beillevaire T, Cathala H-P and Schmitt H (1977) Effect of clonidine on sleep patterns in man. European Journal of Clinical Pharmacology, 12, 319-322.

Bradley PM, Burns BD and Webb AC (1995) Noradrenaline and potentiation in the chick brain slice. Neuroreport, 6, 1501-1504.

Braestrup C (1974) Effects of phenoxybenzamine, acepeprone and clonidine on the level of 3-methoxy-4hydroxyphenylglycol (MOPEG) in rat brain. Journal of Pharmacy and Pharmacololgy, 26, 139-141.

Cedarbaum JM and Aghajanian GK (1977) Catecholamine receptors on locus coeruleus neurons: Pharmacological characterization. European Journal of Pharmacology, 44, 375-385.
Cespuglio R, Gomez ME, Faradji H and Jouvet M (1982) Alterations in the sleep-waking cycle induced by cooling of the locus coeruleus area. Electroencephalography and Clinical Neurophysiology, 54, 570-578.

Darda S (1975) Pharmacokinetics of clonidine. In: Recent Advances in Hypertension, Volume 2 (Eds P Milliez and M Safar), pp. 375-388, International Symposium, Monte-Carlo, Boehringer Ingelheim Laboratories.

Darda S, Foster HJ and Sthle H (1978) Metabolic degradation of clonidine. Arzneimittelforshung, 28, 255-259.

De-Boer T and Ruigt GSF (1995) The selective alpha-2adrenoceptor antagonist mirtazapine (Org 3770) enhances noradrenergic and 5-HT(1A) mediated serotonergic neurotransmission. CNS Drugs, 4, Suppl. 1, 29-38.

Delbarre B and Schmitt H (1971) Sedative effects of alphasympathomimetic drugs and their antagonism by adrenergic and cholinergic blocking drugs. European Journal of Pharmacology, 22, 355-359.

De Sarro GB, Ascioti C, Froio F, Libri V and Nistico G (1987) Evidence that locus coeruleus is the site where clonidine and drugs acting at alpha1- and alpha2-adrenoceptors affect sleep and arousal mechanisms. British Journal of Pharmacology, 90, 675-685.

Drew GM, Gower AJ and Marriott AS (1979) 2-adrenoceptors mediate clonidine-induced sedation in the rat. British Journal of Pharmacology, 67, 133-141.

Florio V, Bianchi L and Longo VG (1975) A study of the central effects of sympathomimetic drugs: EEG and behaviour investigations on clonidine and naphazoline. Neuropharmacology, 14, 707-714.

Forray MI, Andres ME, Bustos G and Gysling K (1995) Regulation of endogenous noradrenaline release from the bed nucleus of stria terminalis. Biochemical Pharmacology, 49, 687-692.

Gaillard J-M (1979) Temporal organization of human sleep: General trends of sleep stages and their ultradian cyclic components. Encephale, V, 71-93.

Gaillard J-M and Kafi S (1979) Involvement of pre- and postsynaptic receptors in catecholaminergic control of paradoxical sleep in man. European Journal of Clinical Pharmacology, 15, 83-89.

Gaillard J-M, Kafi S and Justafre JC (1982) On the role of brain alpha-adrenergic systems in the production of paradoxical sleep. Encephale, VIII, 413-434.

Galliard J-M, Iorio G, Kafi S and Blois R (1983). Paradoxical sleep rebound without previous debt: The effect of minute doses of clonidine in man. Sleep, 6, $60-66$.

Gaillard J-M, Kafi S, Hilaire S and Blois R (1988) Pharmacological considerations on sleep mechanisms. In: Imidazopyridines in Sleep Disorders (Eds JP Sauvanet, SZ Langer and PL Morselli) pp.71-80. Raven Press, New York.

Gothert M, Huth H and Schlicker E (1981) Characterization of the receptor subtype involved in alpha-adrenoceptor mediated modulation of serotonin release from rat brain cortex slices. NaunynSchmiedeberg's Archives of Pharmacology, 317, 199-203.

Groves PM and Wilson CJ (1980a) Fine structure of rat locus coeruleus. Journal of Comparative Neurology, 193, 841-852.

Groves PM and Wilson CJ (1980b) Monoaminergic presynaptic axons and dendrites in rat locus coeruleus seen in 
reconstructions of serial sections. Journal of Comparative Neurology, 193, 853-862.

Head GA (1995) Central monoamines systems and new antihypertensive agents. Clinical and Experimental Hypertension, 17, 141-152.

Kafi S and Gaillard J-M (1981) Effect of alpha-stimulation by clonidine on the evolution of paradoxical sleep in the rat. Journal of Psychiatry and Biological Therapeutics, 1 , 13-20.

Kleinlogel H, Scholtysik G and Sayers AC (1975) Effects of clonidine and BS $100-141$ on the EEG sleep pattern in rats. European Journal of Pharmacology, 33, 159-163.

Langer S (1974) Presynaptic regulation of catecholamine release. Biochemical Pharmacology, 23, 1793-1800.

Lowenthal DT (1980) Pharmacokinetics of clonidine. Journal of Cardiovascular Pharmacology, 2, Suppl. 1; 529-537.

Maj J, Baran L, Sowinska H and Zielinski M (1975) The influence of cholinolytics on clonidine action. Polish Journal of Pharmacology and Pharmacy, 27, 17-26.

Mastrangelo D, De Saint Hilaire, Kafi Z and Gaillard J-M (1994) Effects of clonidine and alpha-methyl-p-tyrosine on the carbachol stimulation of paradoxical sleep. Pharmacology, Biochemistry and Behaviour, 1994, 48, 93-100.

Mauron C, Wurtman JJ and Wurtman RJ (1980) Clonidine increases food and protein consumption in rats. Life Sciences, 27, 781-791.

Paalzow LK and Edlund PO (1979a) Pharmacokinetic of clonidine in the rat and cat. Journal of Pharmacokinetics and Biopharmaceutics, 7, 481-494.

Paalzow LK and Edlund PO (1979b) Multiple receptor responses: A new concept to describe the relationship between pharmacological effects and pharmacokinetics of a drug: Studies on clonidine in the rat and cat. Journal of Pharmacokinetics and Biopharmaceutics, 7, 495-510.

Palacios JM and Kuhar MJ (1982) Beta adrenergic receptor localization in rat brain by light microscopic autoradiography. Neurochemistry International, 4, 473-490.

Reinhard JF Jr and Roth RH (1982) Noradrenergic modulation of serotonin synthesis and metabolism. 1. Inhibition by clonidine in vivo. Journal of Pharmacology and Experimental Therapeutics, 221, 541-546.

Sanger DJ (1983) An analysis of the effects of systemically administered clonidine on the food and water intake of rats. British Journal of Pharmacology, 78, 159-164.

Seidel WF, Maze M, Dement WC and Edgar DM (1995) Alpha-2 adrenergic modulation of sleep: Time of day dependent pharmacodynamic profiles of dexmedetomidine and clonidine in the rat. Journal of Pharmacology and Experimental Therapeutics, 275, 263-273.

Starke K and Altmann KP (1973) Inhibition of adrenergic neurotransmission by clonidine: An action on prejunctional alpha-receptors. Neuropharmacology, 12, 339-347.

Svensson TH, Bunney BS and Aghajanian GK (1975) Inhibition of both noradrenergic and serotonergic neurons in brain by the alpha-adrenergic agonist clonidine. Brain Research, 92, 291-306.

Young WS and Kuhar MJ (1980) Noradrenergic alpha-1 and alpha2 receptors: Light microscopic autoradiographic localization. Proceedings of the National Academy of Sciences, USA, 77, 1696-1700.

(Received 31 October 1996; accepted as revised 27 May 1997) 


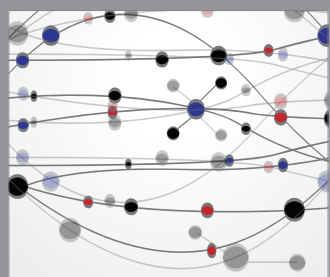

The Scientific World Journal
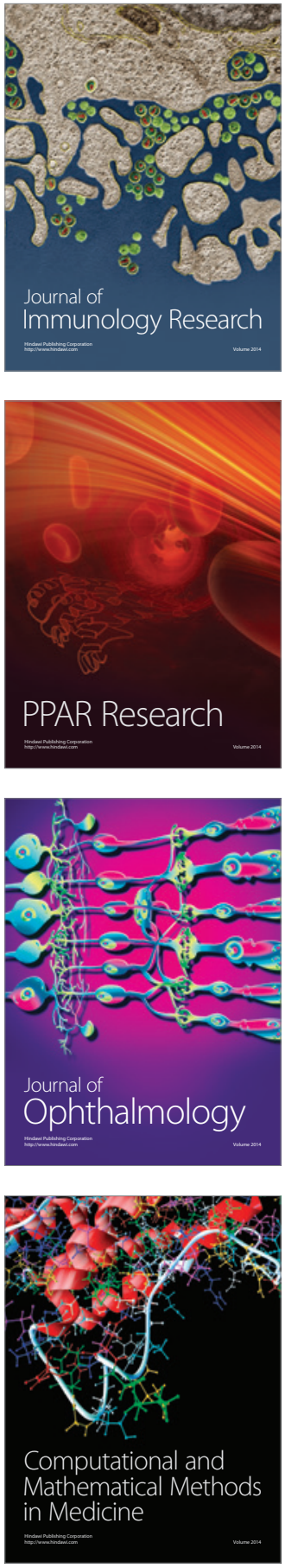

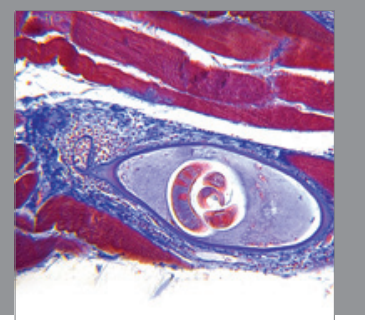

Gastroenterology

Research and Practice
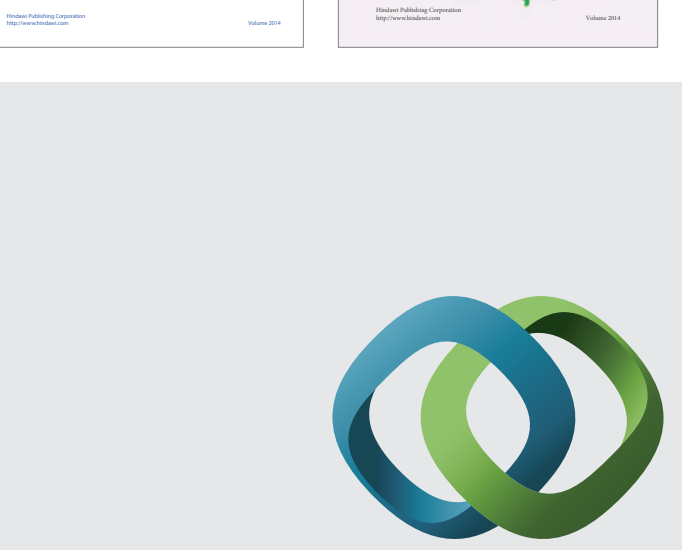

\section{Hindawi}

Submit your manuscripts at

http://www.hindawi.com
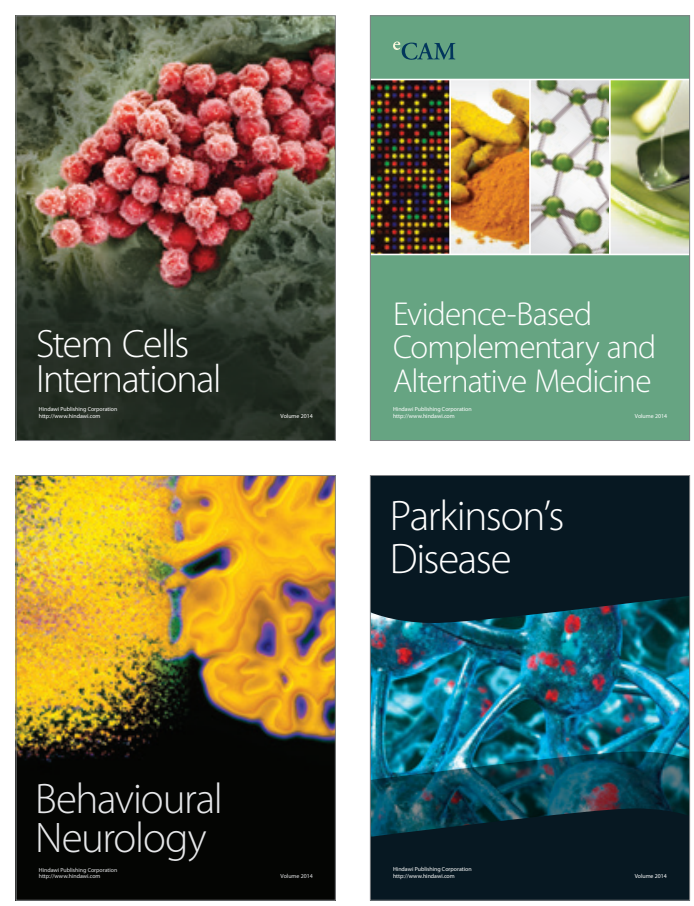

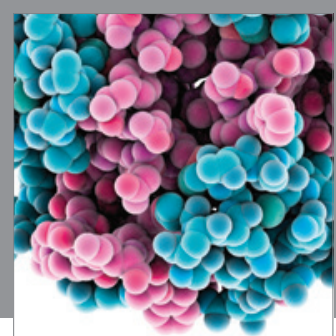

Journal of
Diabetes Research

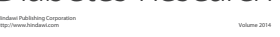

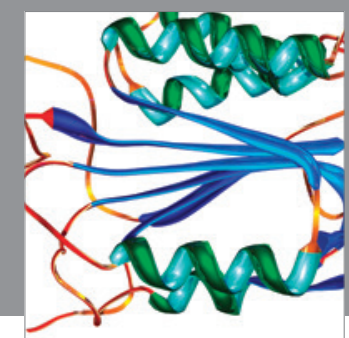

Disease Markers
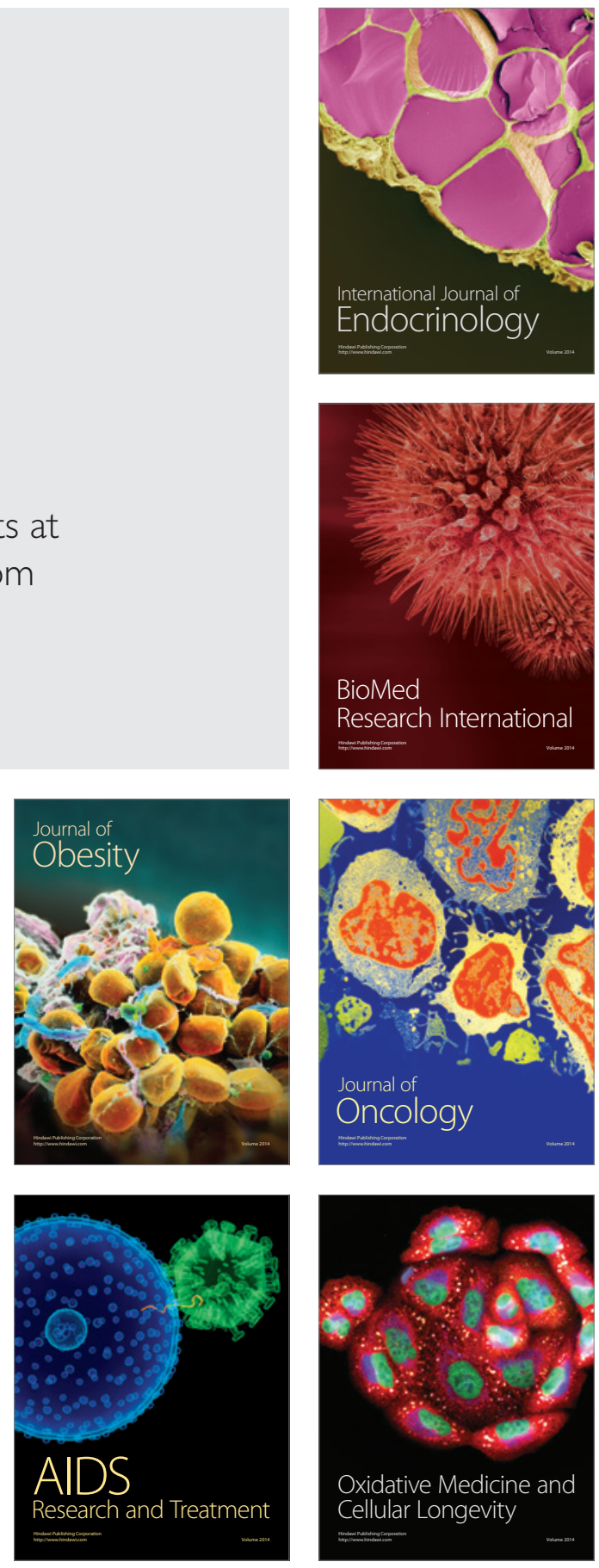